Borneo Journal of Phamascientech, Vol. 04, No. 01, April Tahun 2020

ISSN-Print. 2541-3651

ISSN-Online. 2548 - 3897

Research Article

\title{
ANALISIS NILAI WILLINGNESS TO PAY PER QUALITY ADJUSTED LIFE YEAR TERAPI PENYAKIT MODERATE MASYARAKAT DI KOTA BANJARMASIN TAHUN 2019
}

\section{AN ANALYSIS OF WILLINGNESS TO PAY PER QUALITY ADJUSTED LIFE YEAR OF MODERATE DISEASE THERAPY COMMUNITY IN BANJARMASIN, 2019}

\author{
Melviani*, Setia Budi \\ Universitas Sari Mulia \\ *melviani.apt87@gmail.com
}

\begin{abstract}
ABSTRAK
Pelayanan kesehatan di Indonesia belum maksimal dalam memenuhi kebutuhan pasien dengan penyakit moderate. Pendekatan farmakoekonomi yang paling direkomendasikan dalam rangka kendali mutu dan biaya adalah cost utility analysis. Interpretasi terhadap nilai rasio efektivitas biaya tersebut membutuhkan cost effectiveness threshold untuk menentukan suatu teknologi kesehatan bersifat costeffective atau tidak. Salah satu pendekatan yang dapat dilakukan adalah dengan estimasi nilai willingness to pay per quality adjusted life years. Tujuan penelitian adalah menganalisis nilai estimasi willingness to pay per quality adjusted life year pada penyakit moderate di masyarakat di Kota Banjarmasin dan faktor-faktor yang mempengaruhi WTP per QALY. Metode penelitian menggunakan pendekatan cross-sectional. Survei dilakukan pada masyarakat di Kota Banjarmasin tahun 2019 menggunakan metode stated preference dengan pendekatan contingent valuation. Jumlah sampel sebanyak 100 responden. Instrumen penelitian ini berupa kuesioner yang terdiri dari pengukuran nilai WTP menggunakan metode dichotomous bidding game, pengukuran utility menggunakan EQ-5D berdasarkan skenario hipotetik nilai utility penyakit moderate. Analisis mengunakan bivariate correlation analysis spearman. Hasil penelitian menunjukan Rata-rata WTP per QALY EQ-5D-5L Rp19.538.910 dan analisis variabel karakteristik responden terhadap WTP per QALY di dapatkan R square $0,397(\mathrm{p}=0,026)$ yang artinya bahwa $39 \%$ secara bersama-sama variabel dependen akan mempengaruhi WTP per QALY. Penelitian ini diharapkan dapat memberi masukan terhadap CE-Threshold berdasarkan preferensi masyarakat
\end{abstract}

Kata kunci: Willingness To Pay per Quality Adjusted Life Year, penyakit moderate, EQ-5D-5L 
Borneo Journal of Phamascientech, Vol. 04, No. 01, April Tahun 2020

ISSN-Print. 2541-3651

ISSN-Online. 2548 - 3897

Research Article

\begin{abstract}
Health services in Indonesia have not been maximized to cover the needs of patients who have moderate disease. Furthermore, Pharmacoeconomics approach is most recommended for cost and quality control namely Cost utility analysis. The interpretation of the cost-effectiveness ratio requires a cost-effectiveness threshold to determine whether a health technology is cost-effective or not. One approach that can be used is by finding the estimation of willingness to pay per quality adjusted life years. The research objective was to determine the estimation of willingness to pay per quality adjusted life year for the moderate disease community in Banjarmasin and to find out the factors that influence it. The research method used a cross-sectional approach. The survey was conducted tothe community in Banjarmasin in 2019 by using stated preference methods with the contingent valuation approach. The samplewas 100 respondents. The research instrument was questionnaire which was consisted of measuring the value of WTP using the dichotomous bidding game method, the measurement of utility used EQ5D based on a hypothetical scenario of moderate disease utility value. Analysis used bivariate correlation analysis spearman. The findings showed that the average of WTP per QALY EQ-5D-5L was Rp. 19,538,910 and the analysis of the variable characteristics of the respondents to the WTP per QALY obtained R square $0.397(\mathrm{p}=0.026)$, which means that $39 \%$ of the dependent variable together will affect WTP. per QALY. This research is expected to provide input on the CE-Threshold based on community preferences.
\end{abstract}

Keywords: Willingness To Pay per Quality Adjusted Life Year, moderate disease, $E Q-5 D-5 L$

\section{PENDAHULUAN}

Farmakoekonomi telah

berkembang menjadi disiplin penting dalam subjek ekonomi kesehatan. Analisis farmakoekonomi merupakan cara untuk melalukan penentuan dan melihat pengaruh ekonomi dari alternatif obat atau intervensi kesehatan lain (Andayani, 2013). Metode yang paling direkomendasikan untuk penilaian teknologi kesehatan adalah Cost utility analysis (CUA) karena memungkinkan perbandingkan antara teknologi kesehatan untuk masalah kesehatan yang berbeda sehingga dapat digunakan untuk menentukan prioritas dengan relatif mudah (Venturini et al, 2002; Walley et al, 2004). Interpretasi terhadap nilai rasio efektivitas biaya tersebut membutuhkan cost effectiveness threshold yang digunakan sebagai pembanding dan untuk menentukan suatu teknologi kesehatan bersifat 
Borneo Journal of Phamascientech, Vol. 04, No. 01, April Tahun 2020

ISSN-Print. 2541-3651

ISSN-Online. 2548 - 3897

Research Article

cost-effective atau tidak sehingga dapat direkomendasikan untuk penerapannya dalam intervensi kesehatan (Owens, 1998; Marseille et al, 2015).

Salah satu pendekatan yang dapat dilakukan adalah dengan estimasi nilai willingness to pay per quality adjusted life years (WTP Per QALY). WTP Per QALY mempresentasikan nilai rata-rata kemauan membayar masyarakat terhadap suatu intervensi kesehatan untuk menghasilkan outcome kesehatan sebesar 1 (satu) QALY atau pertambahan usia (tahun) (Bobinac, 2010).

Penyakit moderate memiliki harapan sembuh seperti semula tinggi Sedangkan pelayanan kesehatan di Indonesia belum memenuhi kebutuhan pasien secara maksimal. Namun demikian, perlu adanya kebijakan perawatan penyakit moderate di Kota Banjarmasin yang memberikan arah bagi sarana pelayanan kesehatan untuk menyelenggarakan pelayanan perawatan agar dapat memenuhi hak pasien untuk mendapatkan pelayanan yang bermutu, komprehensif dan holistik.

Tujuan Penelitian ini perlu dilakukan dan dari hasil penelitian ini diharapkan dapat mengetahui nilai WTP PER QALY EQ5D5L dan mengetahui faktor sosiodemografi yang mempengaruhi nilai willingness to pay per quality adjusted life year sehingga Penelitian ini dapat memberikan informasi nilai estimasi WTP per QALY yang dapat digunakan sebagai cost-effectiveness threshold dalam kajian farmakoekonomi.

\section{METODOLOGI}

Penelitian ini menggunakan rancangan penelitian observasional dengan pendekatan cross-sectional. Survei berbasis komunitas dilakukan terhadap sejumlah responden di Kota Banjarmasin untuk kelompok populasi umum (sehat). Estimasi nilai WTP per QALY menggunakan metode stated preference dengan pendekatan Contingent Valuation Method (CVM). Populasi dalam penelitian ini adalah responden populasi umum (sehat) di Kota Banjarmasin. 
Borneo Journal of Phamascientech, Vol. 04, No. 01, April Tahun 2020

ISSN-Print. 2541-3651

ISSN-Online. 2548 - 3897

Research Article

Pengambilan sampel banjarmasin timur, dan banjarmasin penelitian menggunakan teknik barat. Berdasarkan perhitungan stratified multistage cluster dengan didapatkan hasil 100 sampel. memperhatikan lokasi geografis yang Analisis data yang dilakukan dalam dikelompokkan menurut Badan Pusat Statistik (BPS) yaitu banjarmasin penelitian ini adalah bivariate correlation analysis spearman.

utara, banjarmasin selatan,

HASIL DAN PEMBAHASAN

Tabel I. Distribusi Karakteristik Sosiodemografi Responden

\begin{tabular}{|c|c|c|}
\hline Karakteristik responden & $N=64$ & $\%$ \\
\hline \multicolumn{3}{|l|}{ Jenis kelamin } \\
\hline Pria & 25 & 39,1 \\
\hline Wanita & 39 & 60,9 \\
\hline Rata-rata umur & 39 & 39 \\
\hline \multicolumn{3}{|l|}{ Pendidikan } \\
\hline Kurang dari SMA & 40 & 62,5 \\
\hline Lebih dari SMA & 24 & 37,5 \\
\hline \multicolumn{3}{|l|}{ Pekerjaan } \\
\hline Tidak bekerja & 21 & 32,8 \\
\hline Bekerja & 43 & 67,5 \\
\hline \multicolumn{3}{|l|}{ Status pernikahan } \\
\hline Tidak menikah & 13 & 20,3 \\
\hline Menikah & 51 & 79,7 \\
\hline \multicolumn{3}{|l|}{ Jumlah anggota keluarga } \\
\hline Kurang dari 4 orang & 55 & 85,9 \\
\hline Lebih dari 4 orang & 9 & 14,1 \\
\hline \multicolumn{3}{|c|}{ Jumlah anggota keluarga yang di tanggung } \\
\hline Kurang dari 4 orang & 63 & 92,8 \\
\hline Lebih dari 4 orang & 1 & 1,6 \\
\hline \multicolumn{3}{|c|}{ Total pendapatan keluarga dalam sebulan } \\
\hline Rendah (Kurang dari 4 juta) & 53 & 82,8 \\
\hline Tinggi (Lebih dari 4 juta) & 11 & 17,2 \\
\hline \multicolumn{3}{|l|}{ Total pengeluran dalam sebulan } \\
\hline Rendah (Kurang dari 3 juta) & 60 & 93,8 \\
\hline Tinggi (Lebih dari 3 juta) & 4 & 6,2 \\
\hline \multicolumn{3}{|l|}{ Aset yang dimiliki dalam keluarga } \\
\hline Tidak mempunyai aset & 14 & 21,9 \\
\hline Punya aset & 50 & 78,1 \\
\hline \multicolumn{3}{|l|}{ Status dalam keluarga } \\
\hline Bukan Kepala keluarga & 23 & 35,9 \\
\hline Kepala keluarga & 41 & 64,1 \\
\hline
\end{tabular}

Pengalaman dalam Pelayanan kesehatan 
Borneo Journal of Phamascientech, Vol. 04, No. 01, April Tahun 2020

ISSN-Print. 2541-3651

ISSN-Online. 2548 - 3897

Research Article

\begin{tabular}{lll} 
Tidak pernah mendapat pelayanan kesehatan & 22 & 34,4 \\
Pernah pendapat pelayanan kesehatan & 42 & 65,4 \\
\hline Asuransi/jaminan kesehatan & & \\
Tidak mempunyai asuransi & 36 & 15,6 \\
Punya asuransi & 28 & 84,4 \\
\hline Punya masalah kesehatan & & 56,2 \\
Tidak mempunyai masalah kesehatan & 36 & 43,8 \\
Punya masalah kesehatan & 28 & 51,6 \\
\hline Riwayat penyakit dalam keluarga & & 48,4 \\
Tidak mempunyai riwayat penyakit keluarga & 33 & \\
Punya riwayat penyakit keluarga & 31 & \\
\hline
\end{tabular}

Dalam penelitian ini, data demografi digunakan responden wanita $(60,9 \%)$ lebih banyak dibandingkan pria $(39,1 \%)$, Rata-rata usia 39 tahun dan berpendidikan kurang dari SMA $(62,5 \%)$ dengan memiliki pekerjaan (67,5\%). Masyarakat pada penelitian ini lebih dominan menikah $(79,7 \%)$, mempunyai jumlah anggota keluarga kurang dari 4 orang $(85,9 \%)$, jumlah tanggungan dalam keluarga kurang dari 4 orang $(98,4 \%)$, dengan penghasilan kurang dari 4 juta $(82,8 \%)$ dan pengeluaran kurang dari 3 juta sebulan $(93,8 \%)$. Masyarakat dominan mempunyai aset dalam keluarga $(78,1 \%)$, status dalam keluarga yaitu bukan kepala keluarga $(64,1 \%)$ lebih dominan. Masyarakat lebih dominan dengan pengalaman dalam pelayanan kesehatan $(65,6 \%)$, mempunyai asuransi $(84,4 \%)$, tidak mempunyai masalah penyakit $(56,2 \%)$ dan tidak mempunyai riwayat penyakit keluarga $(51,6 \%)$.

Gambaran status kesehatan dengan pengukuran EQ-5D-5L dapat dilihat pada tabel 2 yaitu dimana hasil menunjukan status kesehatan (health state) yang paling banyak adalah 11111 mengindikasikan bahwa masyarakat atau responden tidak ada masalah kesehatan pada pengukuran EQ-5D$5 \mathrm{~L}$.

Tabel II. Distribusi Health state EQ-5D$5 \mathrm{~L}$ responden today ( saat wawancara )

\begin{tabular}{ccc}
\hline $\begin{array}{c}\text { Health state } \\
\text { today }\end{array}$ & Total & $\%$ \\
\hline 11111 & 42 & 66 \\
\hline 11112 & 1 & 1.5 \\
\hline 11115 & 1 & 1.5 \\
\hline 11121 & 8 & 12.5 \\
\hline 11122 & 5 & 7.8 \\
\hline
\end{tabular}


Borneo Journal of Phamascientech, Vol. 04, No. 01, April Tahun 2020

ISSN-Print. 2541-3651

ISSN-Online. 2548 - 3897

Research Article

\begin{tabular}{lll}
\hline 11131 & 1 & 1.6 \\
\hline 11132 & 2 & 3.1 \\
\hline 11221 & 1 & 1.6 \\
\hline 22211 & 1 & 1.6 \\
\hline
\end{tabular}

\begin{tabular}{ccc}
\hline 23332 & 1 & 1.6 \\
\hline 32231 & 1 & 1.6 \\
\hline Total & 64 & 100
\end{tabular}

Tabel III. Deskripsi Health state EQ-5D-5L pada kondisi today berdasarkan masalah

\begin{tabular}{lccccc}
\hline \multicolumn{1}{c}{ Dimensi } & $\begin{array}{c}\text { Level 1 } \\
(\%)\end{array}$ & $\begin{array}{c}\text { Level 2 } \\
(\%)\end{array}$ & $\begin{array}{c}\text { Level 3 } \\
(\%)\end{array}$ & $\begin{array}{c}\text { Level 4 } \\
(\%)\end{array}$ & $\begin{array}{c}\text { Level 5 } \\
(\%)\end{array}$ \\
\hline Kemampuan berjalan & 95,3 & 3,1 & 1,6 & 0 & 0 \\
Perawatan diri & 95,3 & 3,1 & 1,6 & 0 & 0 \\
Kegiatan yang biasa dilakukan & 93,8 & 4,7 & 1,6 & 0 & 0 \\
Rasa tidak nyaman/ nyeri & 70,3 & 21,9 & 7,8 & 0 & 0 \\
Rasa cemas atau depresi (sedih) & 84,4 & 14,1 & 1,6 & 0 & 0 \\
\hline
\end{tabular}

Keterangan: level 1, tidak ada masalah; level 2, sedikit ada masalah; level 3, cukup ada masalah; level 4, sangat ada masalah; level 5, tidak bisa/amat sangat ada masalah.

\section{Nilai WTP per QALY}

Analisis rata-rata WTP per

QALY dapat di lihat pada tabel 4.

Studi preferensi menunjukkan

bahwa nilai WTP per QALY

bervariasi tergantung pada

bagaimana skenario ditentukan

dan instrumen yang digunakan

(Nimdet k et al., 2015).
Tabel IV. nilai WTP per QALY

QALY sebesar Rp Rp19.538.910

bahwa nilai tersebut mencapai 0,43

kali dari GDP perkapita sesuai

dengan kisaran 1-3 kali GDP

perkapita/ QALY yang

direkomendasikan oleh komisi pada

Makroekonomi dan Kesehatan

(WHO, 2005) yang artinya

highly/very cost effective (Marseille et al., 2015).

Hubungan antara karakteristik terhadap nilai WTP per QALY

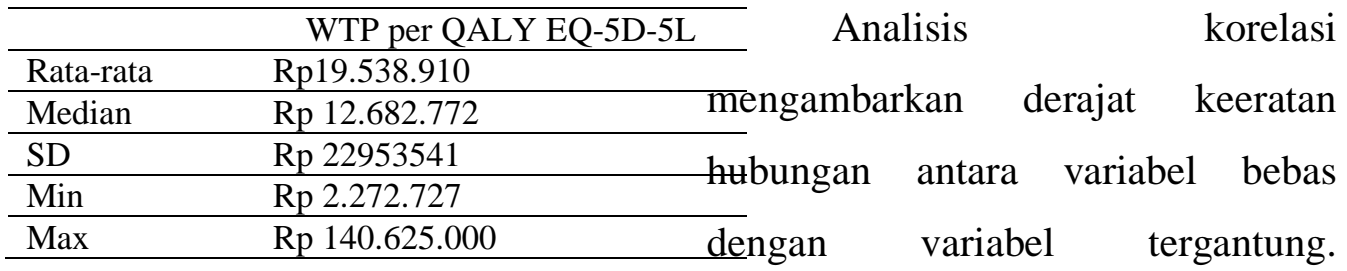

Sesuai dengan GDP perkapita Koefisien korelasi bernilai paling Indonesia tahun 2015, nilai WTP per 
Borneo Journal of Phamascientech, Vol. 04, No. 01, April Tahun 2020

ISSN-Print. 2541-3651

ISSN-Online. 2548 - 3897

Research Article

r mendekati 1 atau -1 maka hubungan

kedua variabel semakin kuat.

Sebaliknya, jika mendekati 0 maka

hubungan kedua variabel semakin

lemah. Tanda korelasi(-) menunjukan adanya arah yang berlawanan, sedangkan tanda(+) menunjukan arah yang sama. Signifikansi antara 2 variabel dapat ditentukan berdasarkan nilai $\mathrm{p}$-value $<0,05$ maka terdapat korelasi antara 2 variabel.

Variabel pendidikan tidak berkorelasi dan kekuatan korelasi lemah, berbeda pendapat dengan beberapa peneliti sebelumnya menyebutkan pendidikan secara signifikan mempengaruhi WTP per QALY(Zethraeus et al., 1997; Shiroiwa et al., 2013; Bobinac et al., 2010; Shafi et al.,2014). Pada variabel pendapatan tidak berkorelasi dengan WTP per QALY dengan kekuatan korelasi lemah, berbeda pendapat dengan beberapa peneliti sebelumnya menyebutkan pendapatan secara signifikan mempengaruhi WTP per QALY(Zethraeus et al., 1997;Shiroiwa et al., 2013; Bobinac et al., 2010; shafi et al.,2014;
Thavorncharoensap et al., 2013). Penelitian yang dilakukan oleh Shafie and Hasaali (2010) menunjukan bahwa tingkat pengetahuan masyarakat berpengaruh terhadap nilai WTP per QALY, berbeda pada penelitian ini, tingkat pengetahuan masyarakat mengenai pengalaman dalam mendapatkan pelayanan kesehatan tidak berpengaruh terhadap nilai WTP per QALY.

Status pernikahan tidak berpengaruh pada nilai WTP per QALY, namun berbeda pada penelitian sebelumnya status pernikahan berpengaruh signifikan terhadap WTP per QALY (Gao., 2015). Peneliti berpendapat bahwa tidak adanya hubungan antara jumlah anggota keluarga dengan kemauan membayar, kemungkinan disebabkan karena jumlah anggota keluarga tidak berkaitan langsung dengan kemauan masyarakat untuk membayar dalam arti ketika diwawancarai kemungkinan responden tidak berfikir ke arah anggota keluarga apalagi sampai berfikir tentang kaitan 
Borneo Journal of Phamascientech, Vol. 04, No. 01, April Tahun 2020

ISSN-Print. 2541-3651

ISSN-Online. 2548 - 3897

Research Article

antara anggota keluarga dengan

dilakukan oleh Bobinac et al(2010)

kemauan membayar untuk kesehatan.

bahwa status kesehatan dengan

adanya suatu penyakit kronis

$\begin{array}{rrr}\text { Status } & \text { kesehatan } & \text { yang } \\ \text { dimiliki } & \text { responden } & \text { tidak }\end{array}$

berhubungan signifikan terhadap

WTP per QALY, sependapat dengan penelitian yang dilakukan oleh Alberini et al (2002) bahwa tidak ada hubungan status kesehatan terhadap kemauan membayar lebih untuk mengurangi angka kematian. Namun berbeda dengan penelitian yang mempengaruhi nilai WTP per QALY. Penelitian yang dilakukan oleh Alberini et al(2002) menunjukan bahwa tidak ada hubungan usia mereka terhadap kemauan membayar lebih untuk mengurangi angka kematian. Namun pada penelitian ini usia ada hubungan terhadap kemauan membayar dengan kekuatan sangat kuat.

Tabel V. Hubungan antara karakteristik terhadap nilai WTP per QALY

\begin{tabular}{lcc}
\hline \multicolumn{1}{c}{ Variabel } & $\mathrm{r}$ & $p$-value \\
\hline Jenis kelamin & $-0,048$ & 0,709 \\
Rata-rata umur & $0,347^{* *}$ & 0,005 \\
pendidikan & 0,069 & 0,589 \\
pekerjaan & 0,117 & 0,359 \\
Status pernikahan & 0,185 & 0,143 \\
Jumlah anggota keluarga & 0,178 & 0,159 \\
Jumlah anggota yang di tanggung & 0,018 & 0,890 \\
Total pendapatan & 0,161 & 0,203 \\
Total pengeluran & 0,211 & 0,094 \\
Aset yang dimiliki & 0,216 & 0,087 \\
Status dalam keluarga & $-0,231$ & 0,067 \\
Pelayanan kesehatan & 0,079 & 0,533 \\
Jaminan kesehatan & 0,204 & 0,106 \\
Punya masalah penyakit & 0,212 & 0,093 \\
Riwayat penyakit keluarga & $-0,059$ & 0,645 \\
\hline
\end{tabular}

Analisis regresi berganda berdasarkan analisis bivariate spearman untuk melihat faktor Pada analisis variabel karakteristik responden terhadap faktor yang berhubungan WTP per QALY

WTP per QALY di dapatkan R square $0,397(\mathrm{p}=0,026)$ seperti pada 
Borneo Journal of Phamascientech, Vol. 04, No. 01, April Tahun 2020

ISSN-Print. 2541-3651

ISSN-Online. 2548 - 3897

Research Article

tabel 6.yang artinya bahwa 39\% secara bersama-sama variabel dependen akan mempengaruhi WTP per QALY dengan taraf kepercayaan $95 \%$, sedangkan sebesar $61 \%$ lainya merupakan faktor diluar penelitian. Menurut fernandes J.M et al (2014) dengan metode EQ-5D-3L, menyebutkan bahwa nilai WTP per QALY sangat bervariasi berdasarkan karakteristik demografi dan sosioekonomi subjek, tapi juga pada sikap mereka terhadap risiko yang didapat.

Penelitian yang dilakukan oleh Thavorncharoensap et al., 2013 menyatakan bahwa nilai QALY bersifat konteks(sesuai skenario) dan mungkin tidak sebanding di seluruh kondisi kesehatan. Gao et al(2015) menemukan hasil yang berpengaruh dalam penelitiannya terhadap WTP per QALY adalah diagnosis. Etnis sangat mempengaruhi WTP per QALY, etnis yang berbeda memiliki biologis, demografis, dan lingkungan sosial serta perbedaan karakteristik psikologis dan perilaku, semua yang berkontribusi terhadap kesehatan seseorang. Perbedaan dalam
Keyakinan sosiokultural di antara ras yang berbeda dapat mempengaruhi berbagai bentuk perawatan diri dan akhirnya mempengaruhi hasil kesehatan (Shafi et al., 2014).

Tabel VI. Hasil analisis regresi linier berganda

\begin{tabular}{rcrrr}
\hline & & & & \\
Model & $\mathbf{R}$ & $\begin{array}{c}\text { R } \\
\text { Square }\end{array}$ & $\begin{array}{c}\text { Adjusted } \\
\text { Rquare }\end{array}$ & $\begin{array}{c}\text { Durbin- } \\
\text { Watson }\end{array}$ \\
\hline 1 & $.630^{\text {a }}$ & 0.397 & 0.209 & 1.876 \\
\hline
\end{tabular}

\section{KESIMPULAN}

Rata-rata WTP per QALY EQ-5D5L Rp19.538.910 dan analisis variabel karakteristik responden terhadap WTP per QALY di dapatkan $\mathrm{R}$ square $0,397(\mathrm{p}=0,026)$ yang artinya bahwa $39 \%$ secara bersama-sama variabel dependen akan mempengaruhi WTP per QALY

\section{DAFTAR PUSTAKA}

Andayani, T. M. 2013, Farmakoekonomi Prinsip Dan Metodologi, $1^{\text {st }}$ Ed Yogyakarta, Bursa Ilmu

Bobinac, A., Van Exel, N.J.A., Rutten, F.F.H., Brouwer, W.B.F., 2010. 'Willingness To Pay For A qualityAdjusted life year : the 
Borneo Journal of Phamascientech, Vol. 04, No. 01, April Tahun 2020

ISSN-Print. 2541-3651

ISSN-Online. 2548 - 3897

Research Article

individual prespective. Value in Health 13, 1046-1055.

Bobinac. A. N. Job A. van Exel, Frans F.H. Rutten, Werner B.F. Brouwer.2012 GET MORE, PAY MORE? An elaborate test of construct validity of willingness to pay per QALY estimates obtained through contingent valuationl. Journal of Health Economics 158- 168

Fernandez JM, Castro EP, CuraGonzalez MI, Cardiel GA, Abraira V, LaCruz AI dan Perez SG. 2014. Willingness to pay for a quality adjusted life year: an evaluation of attitudes toward risk and preferences. BMC health services research 14: 287

Gao, Lan, LiXia, Song-QingPan, TaoXiong, Shu-ChuenLi. 2015. Health-Related Quality of Life and Willingness to Pay per Quality-Adjusted Life-Year Threshold-A Studyin Patient $\mathrm{s}$ with Epilepsyin China .Va lue in health regional issues 6c(2015) $89-97$

Marseille, E., Larson, B., Kazi, D. S., Kahn, J. G. And Rosen, S. 2015, 'Thresholds For The Cost-Effectiveness Of Interventions: Alternative
Approaches', Bulletin of The

World Health Organization, 93(2), 118-124.

Owens, D. K. 1998, 'Interpretation Of Cost-Effectiveness Analyses', Journal of General Internal Medicine, 13(10), 716

Shafie, A.A., Hassali, M.A., 2010 willingness to pay for A pharmacist's dispensing services: A cross-sectional pilot study in the state of penang, malaysia. Pharmacy practice. $8,116-121$

Shafie Aa, Lim Yw, Chua Gn, Azmi M Dan Hassali A. 2014, Exploring The Willingness To Pay For A Quality-Adjusted Life-Year In The State Of Penang, Malaysia. Clinic Economics And Outcomes Research, (6) 473-481 Ncbi

Thavorncharoensap, $\quad$ M., Teerawattananon, Y., Natanant, S., Kulpeng, W., Yothasamut, J. And Werayingyong, P. 2013, 'Estimating The Willingness To Pay For A Quality-Adjusted Life Year In Thailand: Does The Context Of Health Gain Matter?',Clinicoeconomics And Outcomes Research, 5, 29-36

Thavorncharoensap, M. 2014, Measurement Of Utility. $J$ Med Assoc Thai, 97: S43-S49 
Borneo Journal of Phamascientech, Vol. 04, No. 01, April Tahun 2020

ISSN-Print. 2541-3651

ISSN-Online. 2548 - 3897

Research Article

Shiroiwaa, Takeru yoon-kyoung (www.interscience.wiley.com). sungb, takashi fukudac, hui-chu DOI: $10.1002 /$ hec.1481 langd, sang-cheol baeb and kiichiro tsutan. 2010. International Survey On Willingness-To-Pay (WTP) For One Additional Qaly Gained: What Is The Threshold Of Cost Effectiveness?. Health Econ. 19: 422-437 (2010),Published online 20 April 2009 in Wiley InterScience

Venturini, F., Johnson, K.A., 2002, Introduction to Pharmacoeconomic Principles and Application in Pharmacy Practice, California Journal of Health-System Pharmacy 6-14

Walley, T., Haycox, A., Boland, A., 2004, Pharmacoeconomics, Churchill Livingstone, London. 